\title{
25 Research Square \\ Circularly Polarized Monopole Multiband Microstrip Patch Antenna for Multi-Band Operations
}

\author{
Ajay Kumar Meena ( $\nabla$ Ajaykumarmeena_2k17ec10@dtu.ac.in ) \\ Delhi Technological University https://orcid.org/0000-0001-9398-3656 \\ poorv \\ Delhi Technological University \\ Rachit Ravi \\ Delhi Technological University \\ anukul Pandey \\ Delhi Technological University
}

\section{Short Report}

Keywords: Multiband Microstrip, Antenna, multi-band operations, wireless communication, bandwidths, circular polarisation

Posted Date: June 29th, 2021

DOl: https://doi.org/10.21203/rs.3.rs-562875/v1

License: (c) (1) This work is licensed under a Creative Commons Attribution 4.0 International License. Read Full License 


\section{Abstract}

In this communication, an 0-shape multi-band coordinated wideband monopole reception apparatus which supports present-day wireless communication is proposed. This proposed 0 - shaped antenna supports five different bandwidths in the -10db impedance bandwidth range. This antenna was constructed on a FR-4(Fire Retardant fibre glass) epoxy substrate having a dielectric constant ( $\varepsilon r$ ) of 4.4 within the dimensions $60 \times 50 \times 1.59$.This antenna which at the same time have a circular polarisation radiation pattern, which allows the proposed antenna to function at different frequencies. To increase the number of bands and improve the bandwidth, a reverse replica of the 0-shaped concentric ring is introduced in the main design. The proposed antenna is implemented and analysed on Electromagnetic simulation software (HFSS) This replicated antenna provides support to widely used bands such as Bluetooth, WLAN and Ultra-Wideband. An L-shaped split is introduced on the ground to obtain circular polarisation and for matching axial ratio with $\mathrm{S} 11$ bands to achieve circular polarisation. Here the H-plane (azimuthal plane) gives an omnidirectional radiation pattern and E-plane (elevation plane) figures patterns. This design has several advantages like low weight and volume, support linear and circular polarisation and capable of multi-band operations.

\section{Full Text}

This preprint is available for download as a PDF. 